\title{
Simbología del maíz en la cultura andina milenaria: resistencia e identidad del hombre andino*
}

\section{RESUMEN}

Todas las civilizaciones de origen agraria milenaria aún preservan en sus mitos, relatos o iconos representativos a los productos que lograron domesticar y aportar a la nutrición humana y constituyen símbolos de identidad social y legitimidad cultural.

Palabras clave: simbología del maíz; resistencia cultural; aporte mundial

\section{Maize symbology in ancient andean culture: resistance and identity of the andean man}

ABSTRACT

All millenary civilizations of agrarian origin continue to preserve myths, stories and icons that represent their domesticated products. These products contribute to human nutrition and constitute symbols of social identity and cultural legitimacy.

KEYworDs: Maize symbolism; cultural resistance; global contribution.

* Es resultado parte del Proyecto de Investigaciones: «Simbología de las Montańas Sagradas de los Andes» del Grupo de Investigaciones del mismo nombre de la Facultad de Ciencias Sociales, con apoyo financiero del Concurso de Proyectos de Investigación para Grupos de Investigación de la UNMSM 2017, que se presentó en el Congreso Internacional de «Origen y Evolución del Maíz en los Andes», organizado por la Municipalidad Provincial de Cusco y la Universidad de los Andes de Cusco, entre el 16 y 18 de mayo de 2018, como un evento científico interdisciplinario exclusivo para los especialistas a nivel nacional e internacional y al CONEAN de Trujillo, setiembre de 2018. 


\section{Visión y manejo conceptual antropológico de las antiguas sociedades agrarias}

\subsection{Manejo conceptual académico}

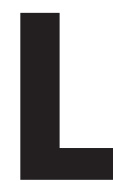

a exitosa empresa de las conquistas y colonizaciones del mundo por la sociedad occidental permitieron forjar mentalidades etnocéntricas para juzgar a los otros pueblos o culturas como no civilizados-cristianos e identificados como salvajes-paganos, por lo que se justificaba el dominio como una obra legítima y piadosa. De forma similar se reproduce durante los siglos XIX y XX como una obra de la sociedad moderna industrial portadora del progreso y desarrollo para las sociedades preindustriales o pueblos étnicos tradicionales.

Desde esta perspectiva, hombres forjadores de la ciencia social reflexionaron en la investigación del mundo académico e influyeron en la creación cultural, con la visión unidireccional y/o con modelos arquetípicos de representar a los "pueblos primitivos" o «salvajes», incluso de las civilizaciones agrarias o sociedades imperiales precolombinas (Azteca e Inka) convertidos en "comunidades indígenas» $\mathrm{o}$ "pueblos étnicos», que alcanzaron solo la concepción mítica de su mundo y no la codiciada visión religiosa y/o la racionalidad moderna.

Entre ellos, H. Spencer (s/f) caracterizó la mentalidad primitiva como mítica, de contenido «inverosímil» o "idea falsa» por "espiritualizar la naturaleza», fantasiosa, absurda o «infantil» y dados a «imitar lo que ven hacer». Similar significado encontramos en el diccionario de la real gramática española como: «fábula, superstición o ficción alegórica».

Mientras, Malinowski (1946: 31, 32, 33) rescata y concibe que el

mito tal como se da en las comunidades salvajes, es decir, en su forma viva original, no es meramente un relato, sino una realidad viviente; no es una ficción como la novela que hoy leemos, sino algo que se cree sucedido en los tiempos primigenios, y que a partir de entonces influye sobre el mundo y los destinos humanos. [...] cumple en la cultura primitiva una función indispensable: expresa, exalta y codifica las creencias; custodia y legitima la moralidad; garantiza la eficiencia del ritual y contiene reglas prácticas para aleccionar al hombre. Resulta así un ingrediente vital de la civilización humana; no un simple relato, sino una fuerza activa tesoneramente lograda.

Levi-Strauss (1990) trata a nivel del problema de conocimiento y señala que "los mitos despiertan en el hombre pensamientos que les son desconocidos", por lo que sería un modo de pensar, de describir y de interiorizar, «igualmente válidas» como lo hacen los investigadores o escritores sociales. Entonces, el "mito tiene significado" y lo que falta es traducir o hacer inteligibles al modo de escribir determinado o de pensar válido. Por eso para William Blake (1989) es una pedagogía educativa de endoculturación o guía de decisiones y acciones, de modo que el mito "garantiza la historicidad» de los hechos sociales y da el sentido de identidad cultural con autoestima y sentido de pertenencia, valoración y clasificación de los «otros».

Hans-Georg Gadamer (1997) cierra el debate fustigando que vivimos en la "época de la razón", de la ciencia o del conocimiento, por lo que se hace necesario saber sobre la religión, el mito y el ritual como "portador de una verdad propia» o por ser la "voz de un tiempo originario más sabio». Es más, «sin el mito resulta imposible comprender la complejidad del mundo contemporáneo», lo que significa que sin el pasado no es posible conocer, explicar ni juzgar el presente y proyectarse al futuro, debido a que las culturas tienen su "condición vital» en los mitos para florecer. Por lo tanto, el «mito» y la «razón» como análisis conceptual son solamente una «historia de conceptos».

\subsection{Formas de pensar y modos de representar de las sociedades agrarias}

a. El trigo y la cebada en la antigua Babilonia. Las antiguas culturas de Babilonia, Egipto, Grecia y Roma, y luego Europa moderna, fundaron su condición de vida y desarrollo con el cultivo del trigo, la cebada, el centeno y la avena. En India, China y Japón con el arroz; así como el Perú y México siguen siendo insignes productores del maíz desde los tiempos precolombinos. Del mijo y la cebada en África.

En las excavaciones del Templo Gobekli Teple, de hace 11600 años en Turquía, se recuperaron muestras de los primeros cultivos de cebada y trigo, dando paso al inicio de la Revolución Neolítica y 
consolidándose en Sumeria y Acadia no solo como los centros productores y de consumo de la cerveza, sino también se vinculan al culto a Asherah (esposa de Yahveh) como la diosa de la fertilidad, «Diosa Madre» o "Árbol Sagrado» de la antigua Babilonia (Wikipedia 2015).

Del mismo modo, el consumo de la cebada y de la cerveza en Egipto está relacionado con el culto a Isis como la "diosa de la cebada y cerveza» o símbolo de la agricultura; mientras «Demeter» es la «diosa de los granos y la cosecha» de los griegos o «inician a las novias y los novios en los secretos del lecho» o es la copulación de la diosa con «Yasio» en el campo de cultivo a costa de su vida (Zeus mató con su rayo) (Graves 1967: 100), que es el «brote del trigo». Y los romanos sustituyen con Ceres como diosa de la agricultura» y festejan "cerealia» en agosto como el «rito de las primicias de la cosecha».

El consumo de la cerveza habría sido opacado por el vino como la bebida de los dioses en el Imperio Romano y luego, convirtiéndose en la bebida del pueblo, de los bárbaros o de los hombres rudos de Alemania y sur de Francia. De modo que su consumo data de hace nueve mil años, aunque actualmente los principales países productores son Estados Unidos, Alemania, Reino Unido, Brasil y China. Sin embargo, la producción y el consumo de los cereales, en especial del trigo, se mundializó y ahora es el "pan del día» en la cadena de alimentación y nutrición humana, aunque en serios problemas por variaciones y enriquecimientos con la intervención de la ingeniería genética y la industria alimentaria.

b. Las uvas y el vino de los griegos y romanos. Dioniso es considerado dios del vino y de la agricultura, quien «hizo que brotara de la cubierta una vid que envolvió al mástil» (Graves 1967: 120), los remos convertidos en serpientes, «llenó el barco de animales fantásticos» y luego se transformó en el «león». Por eso se le considera a Dioniso difusor del culto de la viña en Europa, Asia y norte de África.

Y en el tiempo de los romanos fue el «Dios Baco» el conductor del rito de libación en las "grandes fiestas bacanales» relacionadas con la "vendimia», aunque el año 186 a. C. el Senado romano trató de prohibirlas sin conseguirlo ante el uso arraigado. Y desde entonces, en Grecia y Roma el «vino y la religión» fueron relevantes hasta la actualidad en la tradición cultural del cristianismo y el judaísmo, ya que se consideraba la "sangre de Dioniso", en Egipto era "lágrimas de Horus» o el «sudor de Ra» y Jesús dijo «bebed, esta es mi sangre».

El consumo y el culto de la vid y el vino fueron difundidos por las mujeres, los esclavos y la población popular, convirtiéndolos en el "elemento clave» para las religiones y las civilizaciones agrarias del occidente, y posteriores conquistas y colonizaciones los globalizó en el mundo. Desde entonces, la producción y el consumo están adecuadas a las características propias de las culturas y tradiciones regionales y nacionales, vitalizados por el turismo, el mercado y las ferias de producción original, como en el Perú.

\section{Formas de resistencia y desarrollo cultural andina}

\subsection{Culto a los dioses andinos y la domesticacion del maíz: relatos y formas de representación andina}

Los mitos, ritos y otros relatos andinos revelan las virtudes y funciones de los dioses andinos o de los Apus que moran en las montañas sagradas, mostrando que fertilizan y reproducen las plantas, multiplican los animales y protegen la salud y el bienestar de los pueblos andinos. Incluso, censura el mundo presente de pobreza y de injusticia con su gente y promueve la utopía social andina con el modelo de vida arquetípica del interior de las montańas, donde habría pueblos con bienestar y justicia colectiva, cuyos templos y palacios estarían repujados de oro y plata como signo de su opulencia arcana, con variedad de plantas y animales para la comunidad en general.

Por lo que se examinará la simbología del maíz y su entorno como una de las plantas sagradas preferidas por los dioses a través de las fuentes arqueológicas y etnohistóricas, mientras la etnografía ayudará a mostrar su relevancia en la alimentación de los pueblos andinos de la región central del país y sus formas de representación cósmica desde los tiempos precolombinos:

IIIIIIIII 


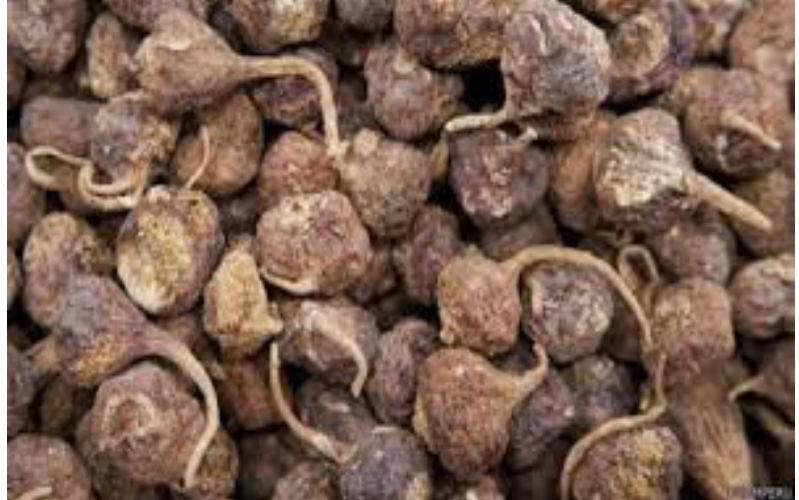

Maka de Junín

fuente proveedora de la hidrobiología como las famosas ranas, peces, aves, totoras, agua y forraje para la ganadería de todos los pueblos ribereños del entorno lacustre, desde tiempos inmemoriales. Aunque en los últimos 50 años ha sido afectado por el «relave mineral» de los centros mineros que drenan por el río San Juan y luego al río y lago Chinchayqocha, de donde nace el río Mantaro y recorre contaminando los departamentos de Cerro de Pasco, Junín, Huancavelica y parte de Ayacucho.

En este gran pajonal y en el litoral de los ríos de "Yawarmayo» (río de mangre) y de "Upamayo" (río Silencioso, formado por la unión de los ríos de Chinchayqocha ${ }^{1}$ y de San Juan) se localiza el sitio arqueológico administrativo de la época Inka, investigación que fue dirigida por Ramiro Matos (1994) con

1 Con las piedras del sitio arqueológico fueron construidas la represa de Tablachaka del río Upamayo y cuando limpian el relave mineral o el lodo rojo depositan en los flancos del río y al secarse se convierte en el polvo fino que se esparce en las tardes de ventarrón o son los endiablados nubarrones de polvo que cubre la planicie, contaminando día y noche el medio ambiente; situación en espera de algún gobernante con algo de autoridad y conciencia de peruanidad pueda intervenir con tiempo. Y del complejo arqueológico sale delineado el "Qapaq Nan» hacia el norte con dirección a la montańa sagrada de "Raku» de Rankas Pampa de Cerro de Pasco, montańa que emerge en la meseta con curiosa forma de un cono oscuro perfecto y su origen describe el mito local siguiente: El «Rey Inka» era muy poderoso y cuando quería avistar la ciudad de Cusco o de Lima, los cerros del lugar eran amontonados más alto para observaba desde ahí; pero, el cerro "Kumaqpunta» de San Pedro de Pari se rebeló al sentirse humillado y por encabezar la conspiración fue castigado por un certero hondazo del «Inka-Rey». Y cuya punta llegó dar a Rankas Pampa, donde permanece hasta hoy como el gran "Jirka Raku» de la comunidad de Rankas. Además, cuentan que el «Inka Rey» a chicotazos ordenaba trasladarse a las grandes piedras que rodaban en fila india para la construcción de la ciudad administrativa de "Pumpun Tampu» y señalan como muestra que aún quedan en las faldas del cerro Raku muchas piedras enfiladas rumbo a la ciudad inka. Mientras el cerro Kumaqpunta quedó con la cabeza mochada y hoy es el «jirka» de San Pedro de Pari (Arroyo 2008).

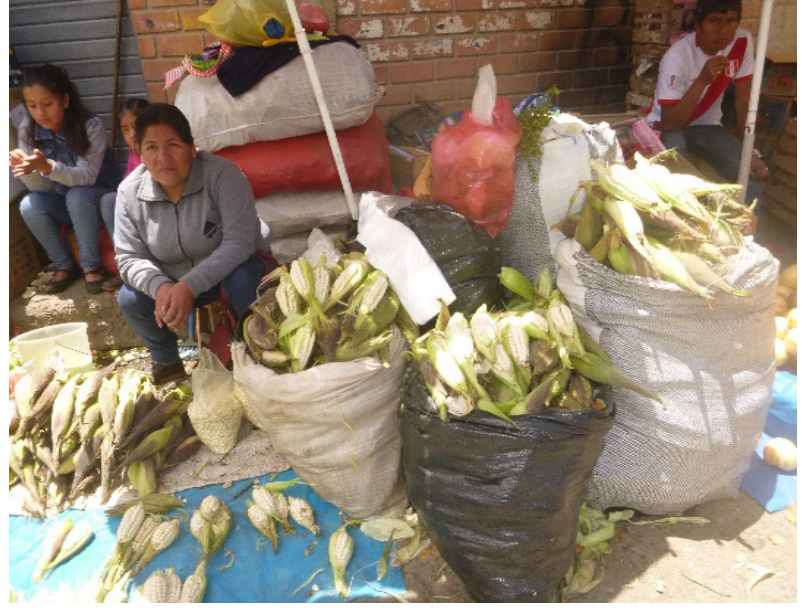

Choqllos de Tarma

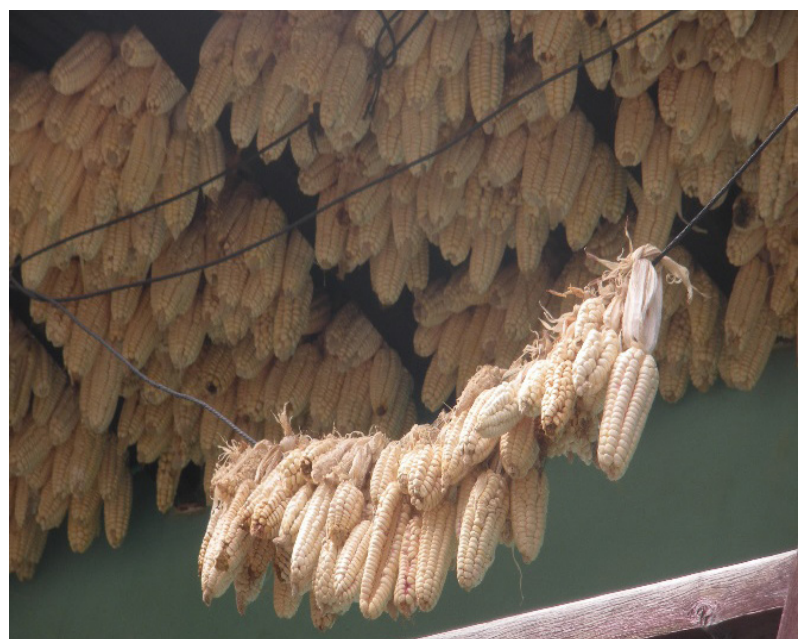

Wayunkas de Tarma

la participación de muchos investigadores nacionales, extranjeros y estudiantes de San Marcos, en distintas temporadas de estudio. Durante las excavaciones del año 1985, en el fogón prehispánico se encontró restos orgánicos carbonizados de la «maka» que por un momento fue confundido con el rabanito, pero la oportuna participación del personal lugareńo de San Pedro de Pari y de Viccu ayudaron a precisar que se trataba de los restos del místico tubérculo altoandino, motivo para el siguiente relato hecho por Walter Pérez de Viccu:

En los tiempos antiguos dios envió al ave «Yukish» a la tierra para comunicarles a las gentes que sus dientes serían de marfil, pero el maldito ave dijo que serían del maíz podrido. Por eso maldicen a yukish que por su culpa tenemos dientes muy débiles que se pudren fácilmente como el maíz. Y en la segunda ocasión, dios habría dicho que los hom- 
bres comerían solo dos veces al día; pero Yukish comunicó que comerían tres veces al día. De ahí desayunamos, almorzamos y cenamos.

Por estas razones, dios dijo muy enojado: «maldita seas, por qué me engańaste, desde ahora buscarás tu comida con los pies maniatados por toda tu vida». Desde entonces dicen que camina con dificultad cojeando sin lograr parar su apetito voraz insaciable, por tener recta las tripas como castigo divino.

También relatan que la Virgen Mercedes tuvo un bebito y un buen día llegó el águila y se lo llevó a un lugar desconocido del cielo donde las aves del mundo se reunieron para distribuirse las partes del cuerpo del «niñito», según el orden de llegada: la washua llevó las uñas para sembrar y crecieron las mejores habas, otras llevaron dientes y crecieron las mejores mazorcas de maíz; de la cabeza las buenas calabazas, de las extremidades crecieron las yucas, del pene brotó las famosas oqas (ocas) de la puna y de los testículos las mejores papas amarillas.

Así concluyeron con distribuirse todo el cuerpo, quedando solamente la "caquita del niño». En eso, muy retrasado y desesperado llegó el ave "wapsaq" de Chinchayqocha y al no encontrar nada, muy triste y abatido por no saber cómo explicaría a su pueblo, miró a todos lados, nada encontró y sólo quedaba la «caquita del niño»; entonces, resignado, llevó a su pueblo los restos del niño y del cual creció y se multiplicó la muy apreciada y afamada «maka² de Junín».

Y por estas razones de la vida, cuando alguien llega muy tarde al almuerzo de la familia, a la fiesta del barrio o al banquete del pueblo, le dicen en son de broma: «has wapsaqueado!». Es decir: «has llegado demasiado tarde como el wapsaq ${ }^{3}$, cuando todo se acabó. Solo queda la...».

2 El olor fétido de la maka (Lepidium meyenii walp) es intenso y trasciende a distancia, muy semejante al excremento humano, en el tiempo de la floración y madurez en las punas del altiplano de Junín. Es muy apreciado como producto con propiedades reconstituyentes y eficaz para fecundar a las mujeres estériles y a los hombres que no logran tener hijos. Ingieren de dos maneras: en las madrugadas como ponche y como chicha para los cumpleańos, fiestas santorales o para los ritos ganaderos.

3 Los lugareńos nos afirman que estas aves aparecen sólo de noche en las chakras de la maka, en el momento de su maduración o la cosecha y nadie sabe dónde viven o de dónde vienen; pero, aparecen sin retraso como indicando que la maka ya están maduras para la cosecha. Entonces, tanto el olor y la llegada de los wapsak son anunciadores que la maka ya estará pronto para la cosecha y su consumo. Aunque, luego de la cosecha la tierra quedaría exhausto o infértil a descansar y recuperarse durante los cuatro o cinco ańos seguidos.
Desde la antigüedad, los pobladores de la meseta y del litoral de Chinchayqocha ${ }^{4}$ proveen de los tubérculos y de los textiles de la fibra de camélidos (y ahora de ovino) a las zonas bajas de Tarma y Ambo de Huánuco y de donde se suministran o intercambian con el muy apreciado maíz y las agradables frutas del valle. Del mismo modo, los pobladores de Canchakucho y de Huayllay acuden o reciben a los negociantes de Canta o de Pacaraos de Lima, quienes aún trajinan por esta ruta intrarregional intercomunicando la costa central con la sierra central. Y en los tiempos precolombinos era controlado y promovido por los de «Pumpun Tampu» (Matos 1994, Arroyo 2004), centro administrativo de la 'epoca inka ubicado en la ruta de "Qhapaq Nan» de Chinchayqocha y frente al sagrado "Bosque de Piedras de Wayllay» 5 .

b. Qanchis Janka de San Pedro de Cajas. Conocidos como los «Siete Hermanos», «Siete Pléyades», «Siete Jirkas» o los «Siete Cerros» en San Pedro de Cajas de la provincia de Tarma de Junín, distrito identificado por los antiguos afamados artesanos de los telares o tapices de la región, que representan la economía, la naturaleza, cotidianidad y el pensamiento de sus pobladores (Arroyo 2008).

Según la ilustración del profesor jubilado Julián Loja, gran depositario y difusor de la cultura andina de Tarma, dice que los «Siete Cerros» de San Pedro de Cajas estaría relacionado con el mito de origen del dios costeño "Pachaqamaq" (Pachacamac), como creador del mundo, de las plantas y animales, pero al ver que no había la humanidad invocó a las «Siete Estrellas» (Onqoy o pléyade) que descendieran con sus respectivas esposas a poblar el mundo, ubicándose en el territorio de Tarma y desde donde se distribuyeron el territorio: al menor le asignaron la parte alta, fría e inhóspita para la producción de variedad y agradables papas; los mayores se apropiaron de las prósperas cuencas con riego de Acobamba, Vilcabamba, Huaracayo, Tapo y La Unión, para la domesticación

4 En la visión andina es de consenso que las lagunas estén asociadas a los mitos de origen, como de Chinchayqoocha habría salido una mujer con su llama y se casó con el pobre Millay de una sola llama vieja y luego se convirtió en un rico lugareño con cientos de camélidos, hasta que por un chasco todo perdió al instante (Arroyo 2008).

5 Según el mito, la selva central llegaba hasta el actual pueblo de Huayllay para el beneficio de sus pobladores, pero por olvidar el culto a sus dioses fueron castigados: la selva lo retiró hasta el lugar actual y al bosque, sus animales y sus gentes fueron convertidos en el «Bosque de Piedras de Wayllay». 
y abundancia de los mejores frutos del maíz sagrado de los dioses y como para honrar el mito, son pueblos y distritos productores de las mejores variedades ${ }^{6}$.

Y como vivían felices y en abundancia, olvidaron a su creador, quien les castigó con el diluvio anegando y destruyendo la región. Los hermanos se refugiaron en la casa del hermano menor maltratado, pero todo se destruyó y los «Hermanos Waman» se convirtieron en las «Siete Jirkas» para cuidar a las generaciones venideras, con autoridad y prestigio en la frontera con los «antis» de Chanchamayo, conocidos por los nombres emblemáticos siguientes: Rashta Waman, Poqoy Waman, Tamia Waman, Orqo Waman, Punky Waman, Rikra Waman e Indio Waman. Divinidades con terminologías y atributos ligados a las características del medio hábitat y de economía productiva, relacionados con el culto a la fertilidad de los dioses de la agricultura: nevado, lluvia, montańa y ciclos productivos.

c. Cerro Wayunkayoq de Acobamba. Significa «Cerro Colgante» del distrito de Acobamba de Tarma, para testimoniar los antiguos conflictos y dominios de dos pueblos vecinos en condiciones, actividades y etnias diferentes, asociados a dos sitios arqueológicos precolombinos: Pumampi (Ñawpa Marka) y Tupín (Tupis). Según el relato, el antiguo dueño y gobernante de Pumampi era rico, poderoso y dueño del maíz, mejor en variedad, calidad y cantidad de la cuenca, y también tenía una hermosa hija joven que recorría jovial y decorosa la chacra del maizal, cuando de pronto un hambriento joven apuesto de Tupín rodó hasta el manantial "Ushqo Lopa» (Gato Montés), donde se conocieron y se enamoraron y, con el «don» del amor, la ńusta entregó una "wayunka de maíz» para salvar la hambruna del pueblo vecino.

No obstante, el padre odioso, avaro y vengativo, como escarmiento sancionó de muerte a su hija, colgándola en el cerro que hoy lleva el nombre de "Wayunkayoq" y también el enamorado murió pidiendo clemencia, convirtiéndose en los manantiales de Matara y hoy es la mejor zona maicera de la cuenca de Acobamba. Desde entonces, los hombres

6 Y en el mercado actual de Lima, el maíz de Tarma es un producto distintivo para la región central de Huancayo, aunque en serio peligro de degenerarse por la sobresaturación y contaminación de la tierra, amenazada por la tecnología productiva moderna, además de los efectos de los centros mineros. mueren con las galgadas de piedras que caen del cerro Pumampi y las mujeres con las del cerro Wayunka, respectivamente. También, desde Pumampi se propalaron mejores maíces dando renombre a la cuenca de Tarma y, del mismo modo, los productores son identificados por sus mejores "wayunkas de maíz» que penden de las vigas del techo interior, en memoria a la generosa ñusta de la región.

\section{d. Complejo religioso de Wamanrasu de Huancavelica.}

Los departamentos de Junín, Huancavelica y Ayacucho desde tiempos inmemoriales mantuvieron relaciones permanentes de economía, política e historia cultural religiosa. $\mathrm{Y}$ en el aspecto religioso andino es de especial relevancia encontrar el culto dentro de la organización del parentesco de tres «Apu Wamani» de rangos mayores que identifican y representan a las tres regiones étnicas culturales: el «Apu Wamanrasu» de Huancavelica como el hermano mayor, seguido del «Apu Qarwarasu» ${ }^{7}$ de Puquio (sur de Ayacucho) y luego el "Apu Rasuwillka» de Huanta (norte de Ayacucho); incluso, el "Apu Waytapallana» de Huancayo es considerado otro hermano (Arroyo 1987, 2008).

En el concepto religioso y productivo de los pueblos andinos, los tres dialogan como los Apus mayores y representantes de las tres regiones culturales: unas veces intercambian sus bienes recíprocamente y en otros momentos se convierten en dioses caprichosos y temerarios que compiten con sus riquezas o disputan como los bravos guerreros con sus "warakas" (hondas) por emulación y conquista de sus territorios y fronteras culturales de confluencia, como un modo de actualizar sus poderes y autoridades de ser los Apus mayores interregionales sobre los dioses locales. Asimismo, restablecen y fortalecen sus vínculos de parentesco, alianzas políticas y cohesiones culturales en redes regionales, zonales y unidades comunales.

Dentro de este modelo de organización espacial y relaciones de solidaridad y de intercambio, el Apu Wamanrasu redistribuye sus ricos minerales de oro, plata y azogue y la cosecha de los tubérculos y cereales de su jurisdicción; mientras el Apu Qarwarasu es rico en la ganadería y envía sus vacunos, alpacas y vicuñas montaraces para el vestido. Del mismo modo, Apu

7 Guamán Poma registra como los principales «Wakas» del Tawantinsuyo y entre ellos menciona a Qarwarasu y Rasuwillka entre los más reconocidos del Chinchaysuyo. 


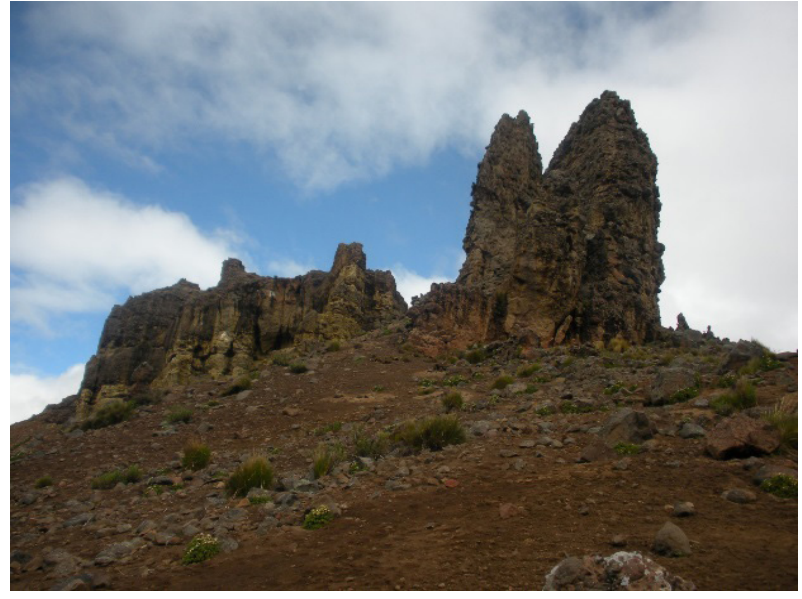

Bosque de piedras

Rasuwillka, dueńo de la selva y del valle de Huanta, es el abastecedor de maíz, coca y de ricas y frescas frutas como la lúcuma, chirimoya, osón y pacae, entre otros. Mientras el Apu Waytapallana se distingue por producir un gran muestrario botánico místico de hermosas y variadas flores de los Andes y distribuye en sus ámbitos regionales para la gran fiesta del «Tayta Shanty» o "Santiago» del 25 de julio al 1 de agosto de la sierra centro-sur del país.

Con estas tradiciones religiosas, productos variados por pisos ecológicas y las ferias regionales se integran continuamente los pueblos andinos, expresados y representados por sus divinidades andinas y fiestas santorales, como son los carismáticos «Santos Patrones»: el «Señor de Wayllay» de LircayHuancavelica y el "Señor de Maynay» de HuantaAyacucho. $\mathrm{Y}$ en esta lógica la red santoral andina se amplía al norte con el culto al "Señor de Muruway» de Tarma-Junín y el «Señor de Wayllay» de HuayllayCerro de Pasco; incluso, desde estos ejes religiosos de origen precolombino se amplían a otras esferas locales y regionales del mundo andino, dentro de la red religiosa y sistema ecológico (Arroyo 2008).

Estos santos patrones, como íconos modernos, dinamizan y garantizan el mercado local e interregional de la sierra central del país, como pueden constatarse en las ferias semanales o periódicas alrededor de las fiestas santorales de los meses de mayo y setiembre, encubriendo la racionalidad organizacional y el principio territorial de los dioses andinos: tópicos en espera de futuros estudios sistemáticos por especialistas que expliquen la visión andina actual, alrededor del «Qapaq Nan».
Por el momento mostramos el complejo religioso de Wamanrasu ubicado entre las comunidades emblemáticas de Santa Bárbara y San José de Astobamba, porque en la frontera de ambas comunidades se encuentran el mayor "Apu Wamanrasu» y los hermanos menores y locales están a sus lados: al sur el «Apu Qarwarasu» y al oeste el "Apu Antarasu» del distrito de Santa Ana. Y alrededor del imponente macizo Wamanrasu se ubica un conjunto de espacios simbólicos articulados de connotación histórico-cultural (Arroyo 2016), con matices siguientes:

d.1. Bosque de piedras y el altar del apu mayor. En el centro del bosque de piedras se ubica la «Mesa» o el "Altar del Apu Wamanrasu», donde evocan y depositan las ofrendas en la fiesta ritual de las alpacas, llamas, vicuñas, las ovejas y los vacunos de la comunidad de Astobamba, desde tiempos primigenios.

d.2. La cueva de las siete calaveras y el entierro precolombino. En el abrigo rocoso encontramos el antiguo entierro múltiple muy disturbado, donde las cámaras funerarias de estructura lítica unida con argamasa de barro están totalmente destruidas y los restos óseos amontonados en la intemperie. Este entierro indica el deseo de la casta privilegiada de la época precolombina de seguir viviendo al lado de la montaña sagrada y del apu mayor de la región, equivalente al paraíso del dios cristiano; seguramente los futuros estudios arqueológicos permitirán esclarecer el sentido del entierro funerario que debe estar relacionado con los restos arqueológicos ubicados en el antiguo pueblo de San José de Astobamba, abandonado desde la época de la guerra interna.

d.3. Camino y apacheta en la ruta a Wamanrasu. Don Teodoro Lucas, de la estancia de Ciénega-Pata de Astobamba, afirma haber encontrado y caminado por un sendero que se dirige por la cumbre donde hay una apacheta antigua y se pierde en el nevado Wamanrasu. Posiblemente sea un camino sagrado antiguo para ofrendar al apu mayor, como se encontraron la «Momia Sarita» del "Apu Sara-Sara» al sur de Ayacucho o a la «Momia Juanita» del "Apu Ampato" de Arequipa.

d.4. Choqllo sagrado y la serpiente bicéfala en la laguna sagrada de Yawarqocha. En la parte baja del lado noroeste de la "Cueva de las Siete Calaveras» se sitúa la laguna sagrada de "Yawarqocha» (laguna de sangre) y es considerada como "encantada» y peligrosa porque en ella habita una "serpiente bicéfala» que 
protege al "choqllo sagrado" que crece en sus inmediaciones y devora a todo extrańo que se aproxima a su alrededor.

La importancia de este relato es por contener el significado de la mítica serpiente bicéfala asociada al «maíz sagrado» en la figura del «choqllo» en una laguna altoandina, que es símbolo del culto a la fertilidad relacionado al significado de los ancestros enterrados en el abrigo rocoso y reconocidos por los «mallkis» o las semillas cósmicas como el "maíz sagrado", que se ofrenda al «Apu Wamanrasu», también considerado como el «Dios de la Fertilidad»o «Dios Sembrador», según infiere Rebeca Carrión (1959).

d.5. Las galgadas de maiz sagrado y los loros de cabeza roja. La montańa sagrada de Wamanrasu, además de su significado del "Apu Mayor» es el centro del encuentro o separación de los antiguos caminos precolombinos y aún son vigentes en la actualidad, por los comerciantes o «llameros» altoandinos de los distritos de Huancavelica. Por el lado sur y debajo del frontis de la montaña (estancia de Wamanrasu de Santa Bárbara) cruza la red del camino vial intrarregional que se separa del "Qhapaq Nan», en las alturas del pueblo de Paucará-Acobamba, para dirigirse al sitio administrativo inka de Tambo de Mora de San Clemente de Pisco-Ica. Además, desde este punto se separa otro camino rumbo a las quebradas maiceras de Lircay, muy transitado en los meses de julio y agosto, tiempo de la cosecha y de la fiesta de "Santiago", para comprar o intercambiar sacos de maíz y abastecerse hasta la próxima cosecha, en son de la fiesta del ganado y culto a las divinidades de la región.

Estos viajeros ruteros de recuas de llama o acémilas y los lugareños de la estancia aseveran sobre el descanso de los "loros de cabeza roja» en las faldas de la montańa sagrada de Wamanrasu, donde comen el maíz sagrado en bandadas con gritos escandalosos que hacen caer los granos como galgadas hacia el camino. Además, es el tiempo de tránsito de las bulliciosas bandadas de loros de cabeza roja, que atraviesan por la altura de la ruta y abra de Wamanrasu para dirigirse a la yunga de San Clemente-Pisco, productores del apreciado choqllo o maíz y de las frutas, así como para retornar a las cuencas maiceras del río Mantaro y del río Urubamba.

d.6. Regalos del apu Wamanrasu a los viajeros de la ruta. Al pie del cerro Wamanrasu existe un abrigo rocoso por donde pasa el antiguo camino intrarregional

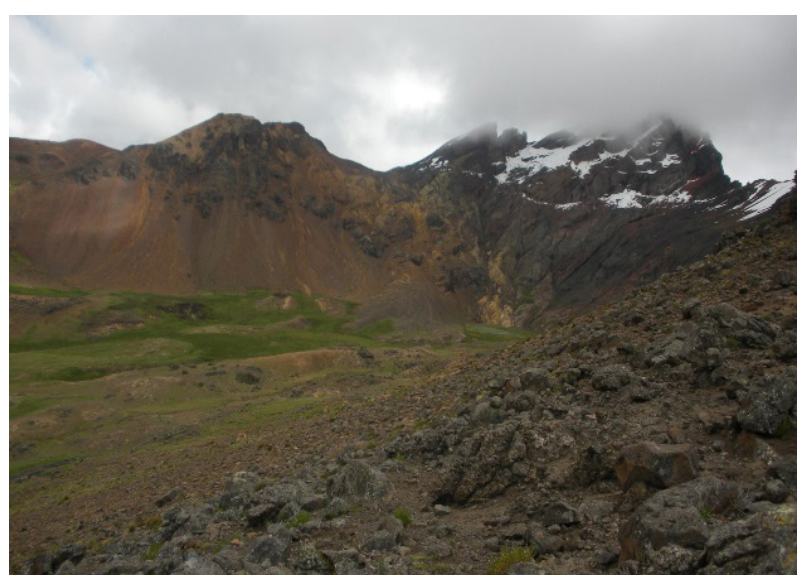

Laguna Yawarqocha

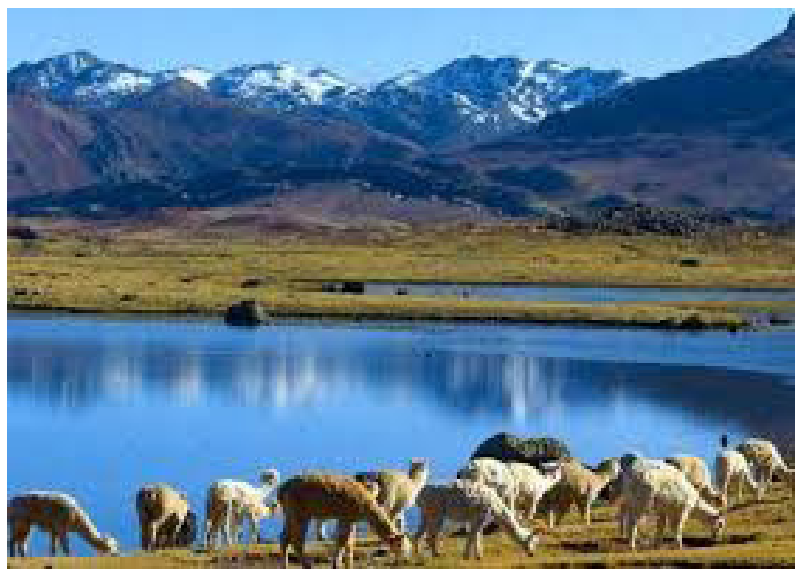

Laguna Paqoqocha

de uso actual y según la referencia de los lugareños, en tiempos antiguos un joven y novicio comerciante se hizo tarde y descansó en dicha cueva, y entre sueños escuchó el diálogo iracundo de dos señores mayores: Wamanrasu preguntando de aquel que «descansa en su hotel» y Qarwarasu informa ser el hermano menor pobre y engañado por su hermano mayor y rico, ambicioso y tramposo; por lo que el primero ordenó regalarle un saco del «maíz blanco».

Cuando despertó en la mañana, efectivamente, tenía al lado un "saco de maíz», quien alegre y reconocido retornó del viaje; pero a medida que se aproximaba a su casa la carga se hacía más pesada y dura. Para su sorpresa, el «maíz blanco» se había convertido en un «saco de plata» y él en el más rico del pueblo.

Este relato de control social moralizadora, concluye con el castigo ejemplar del hermano mayor avaro, quien no conforme con su riqueza, también intentó trampear al «Apu Wamanrasu». Pero, según don 


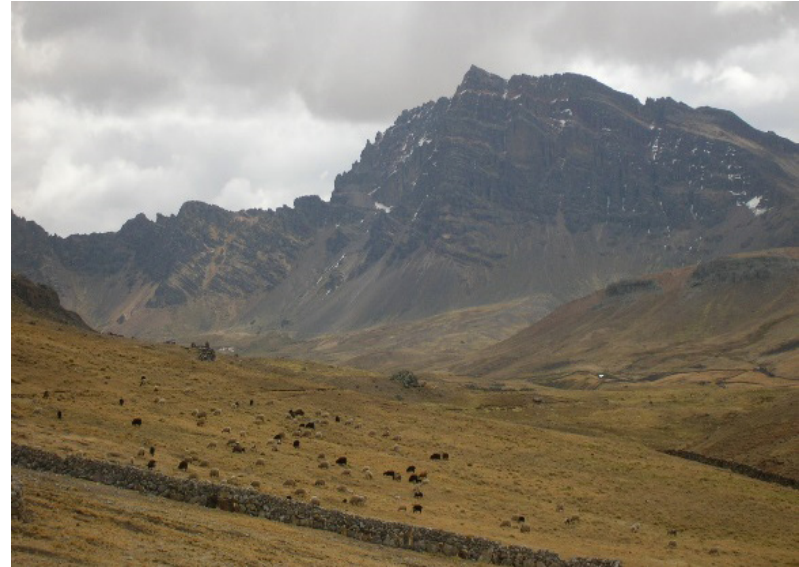

Apu Rasuwillka

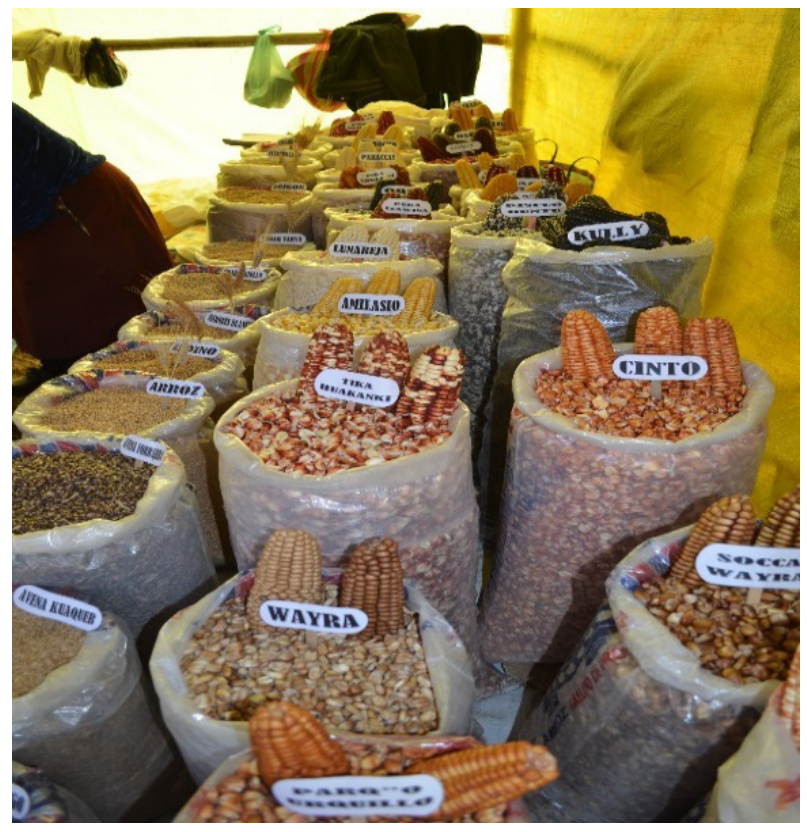

Variedad de maíz peruano

Donato Morán de la Estancia de Qarwarasu, los apus son conocedores de las intenciones de la "gente mala y ambiciosa", "todo lo sabe y todo lo puede», nadie puede engañarle y castiga con severidad a todo infractor, así como a los cazadores furtivos de sus vicuñas.

\section{e. Las paqarinas de la laguna Choqlloqocha y} Paqoqocha de Castrovirreyna. Ubicadas en la parte altoandina de la provincia occidental de Huancavelica, se distingue como zona ganadera de los camélidos (alpacas, llamas y vicuñas) en la meseta, con humedales y hermosas lagunas como Choqlloqocha (4605 msnm) — «laguna de Choclo»
(Choqllo) - que según el mito de origen es reconocido como la "paqarina» de los "Chankas» y durante la guerra étnica preinka, los «Wankas» derrotados logran huir ligeros arrojando sus cargas de maíz a la laguna y cuando esta se redujo de volumen por la sequía y el calor, en la ribera habrían crecido hermosos y tiernos choqllos (Rostworowski 1988), desde entonces se le conoce por Choqlloqocha (laguna de Choqllo). También de la laguna de «Paqoqocha» (laguna de paqo o alpaca) habrían emergido las primeras alpacas crianderas para multiplicarse y prestigiar a los habitantes altoandinos.

Navarra del Águila (1983) presenta un antiguo relato del origen de las tribus de "Ankcu Wallok», en que los dioses advinieron para que tres hermanos activos emergieran de Choqlloqocha para ordenar a los pueblos que vivían en permanente guerra y enseñarles a cultivar plantas y criar ganados para su sustento. Luego, concluida la misión se convirtieron en gobernantes y en dioses: «Apu Waman» (dios Halcón) para los Pokras de Ayacucho, "Apu Oskqo» (dios León) para los Chankas de Apurímac y el "Apu Atokc» (dios Zorro) para los Wankas de Huancayo. Además, Navarro (1983: 54) precisa que existían otros dioses: «Taita Urkco o Apu Wamani (dios cerro), el que da la fertilidad a la tierra i la hace producir, el que da fecundidad al ganado i lo hace procrear». Por estos beneficios, los lugareńos reconocieron y siempre ofrendaron con las mejores flores, «mujeres vírgenes», mazorcas de maíz ("Apu Zara Mama»), quintos de la mama coca, wayruro, llampu, kuti y otros elementos rituales. Tradición vigente en todas las comunidades de la región durante el rito de propiciación del «pagapu».

f. Apu Rasuwillka y el maiz del valle de Huanta. La montaña sagrada de Rasuwillka se sitúa en la cordillera oriental de la provincia de Huanta, Ayacucho, las comunidades y los pueblos vecinos lo reconocen como el «Apu» más poderoso, rico, dueño y productor de las ricas y frescas frutas de los ríos Apurímac, Ene y Mantaro (VRAEM) y de las mejores variedades de maíces de los pagos del valle de Huanta (Waywas, Makachakra, Huamanguilla, Rosario, Matará, Luriqocha, etc.). En la fiesta del «Señor de Maynay», mes de setiembre, organizan la gran feria agropecuaria para la exposición de los mejores productos de la región y comercializan con los pueblos 
de otras regiones, entre ellos la gran variedad del maíz blanco y morado. Asimismo, para patentizar estas relaciones económicas y vínculos culturales milenarias, en la cosmovisión andina representan la actividad ocasional y de prestigio del «Apu Rasuwillka», que intercambia recíprocamente con sus dos hermanos mayores: Wamanrasu y Qarwarasu.

\section{g. Apu Qarwarasu y Apu Sara-Sara de Puquio y} Pausa. La montaña y "Apu Qarwarasu» es otra divinidad ostentosa ubicada en el sur de Ayacucho, como señala Arguedas: «Los wamanis son las montañas, Señor Wamani. Hay mayores y menores. Don Pedro es el mayor de los wamanis de Puquio; pero de los wamanis de la región, hasta donde los naturales de Puquio consideran como zona familiar, el Qarwarasu es el mayor wamani» (1981: 46).

El profesor Juan Escajadillo narra el drama de los antiguos dioses antiguos de Puquio, donde «SaraSara» abandona a su esposo "Qarwarasu» por infidelidad, retirándose a su región para convertirse en el "Apu Sara-Sara» (Apu Maíz-Maíz) de Pausa y proteger a "Qasiri Warmi Llaqta» (Pueblo de Mujeres sin Marido) (Arroyo 2014) y beneficiar a todos los pueblos de su confín, especialmente a Qellqata como el pueblo maicero de la zona. En cambio, Qarwarasu al quedar solo obligó a sus hijos cultivar el maíz para subsistir y luego se convirtió en el actual «Apu Qarwarasu» de Puquio, favoreciendo a Andamarka, Aukará, Waykawacho, Sondondo y otros pueblos distinguidos en el cultivo de los mejores maíces en los bellos y formidables andenes de las comarcas. Por eso, todos lo reconocen, evocan y tributan como el «Apu Mayor» de la región.

\subsection{Simbología del maíz en el universo mítico y la religión andina (mitos, ritos y otros acontecimientos)}

a. Referencia cientifica del origen del maiz. Como resultado de las excavaciones arqueológicas en «Los Gavilanes» de Huarmey por Bonavia y Grobman (1982) se calculó la edad del maíz en el Perú de 5000 años, cuando para México se registraba de 7000 años. La importancia de este estudio es haber mostrado las tres variedades de maíz pertinentes a su tiempo: «proto-confite morocho", "confite chavinense» y "protokculli». Luego, estudios realizados entre 2007 y 2011 en Paredones y Huaca Prieta del valle de Chicama (Trujillo) permitieron la nueva datación entre 6504 y 7775 años, con lo que sentó el origen antiguo del maíz peruano domesticado.

Desde entonces hasta la actualidad, la trayectoria del maíz peruano es de multiplicar y diversificarse en la producción y la representación religiosa de los habitantes de muchas regiones y pisos ecológicos del país. Aunque el consumo del maíz silvestre es más antiguo, pues ya aparece en la dieta de los trashumantes de la cueva Guitarrero (Áncash), Pikimachay (Ayacucho), Telarmachay y Chivateros, entre otros.

Corroborando la datación señalada, Sumar (2018: 9), especialista en el estudio del maíz, sostiene que el maíz es de origen peruano y que luego se difunde; como resultado de décadas de estudio y comparación de teorías, también como agricultor de la cultura y tradición del maíz, en la apertura de su último libro declara: «Tengo 80 años y 75 de ellos estuvieron atados a la agricultura//. Todavía recuerdo, como si fuera ayer, la felicidad que sentía de niño, cuando tocaba adornar con mazorcas de todos los colores, el anda del patrón de los agricultores, San Isidro 'El labrador', para llevarlo a pasear por las calles de los pueblos del Valle Sagrado de los Incas, acompañado siempre por bandas de caperos».

\section{b. Dios sembrador y el maíz sagrado del antiguo} Perú. Rebeca Carrión, luego de estudiar «El culto al agua en el antiguo Perú», representación del sistema de riego y de la productividad a través del análisis de la escenografía del material arqueológico, toma interés en el «arte del sistema simbólico» en cuanto a la lectura de los personajes y su asociación con plantas, frutos y animales en un contexto de la trama ritual, que revela «La religión en el antiguo Perú» (1959).

En este caso, interesa mostrar la simbología del maíz y el papel de los dioses fundadores para contrastar con nuestros materiales etnográficos (Arroyo $1978,2004,2008,2016)$ sobre el dios creador antiguo de quien su poder fuera honrado y reconocido en su propio templo y ahora, desde la conquista hispana, se encuentra alejada en las montañas sagradas identificadas con diversos hipónimos, según la lengua y dialecto de las regiones, que mostraremos más adelante. Además, nos permitirá a conjunciones de los diversos animales y plantas que aparecen indis- 


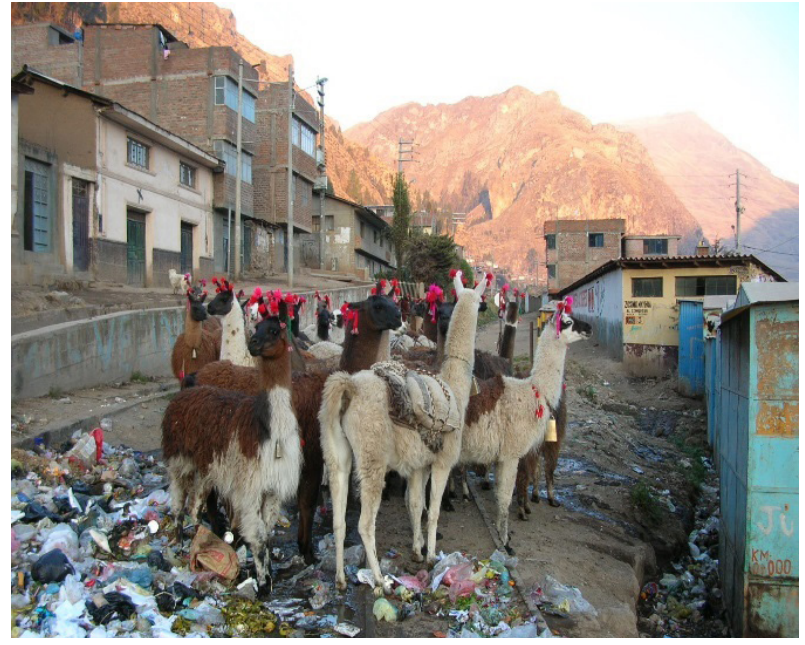

Las Ilamas viajeras de Huancavelica

tintamente en los mitos, relatos y acontecimientos actuales que el hombre andino reflexiona, construye y opera en su cotidianidad agropecuaria y actividades rituales para aleccionar a sus descendientes; mientras en las iconografías precolombinas sintetizan en el culto y representación a sus dioses.

Como señala Rebeca Carrión, en la figura 23 (1959: 42) describe la composición de un cántaro sobre el «sacrificio de un auquénido en honor al Dios de la Fertilidad», cuyo personaje es un dios con dos báculos (adornados con los choclos) que descansa sobre las cabezas de los loros y en ambos lados aparecen la figura de los felinos aullando, cinturón del dios de serpiente bicéfala y acompańado por el oferente sacrificador de un auquénido. Y hoy los pastores de la Unión de Arequipa y de Puno siguen sacrificando a sus llamas durante el rito de propiciación de sus camélidos, en la «Tinka de Alpaca» o la «Wylancha».

En el mito del dios "Cuniraya y Cahuillaca» (Ávila 1598/1966: capítulo 2), aparece un conjunto de animales que le encaminan al dios huarochirano que persigue a su amada, según sus lealtades fueron adquiriendo sus cualidades que permanecen hasta hoy en la tradición de los pueblos andinos, entre los citados están el cóndor, el zorrino, el puma, el zorro, el halcón y el loro.

Todos estos animales silvestres, sumado la vizcacha y la vicuńa, son animales sagrados de los apus que residen en las montańas sagradas (Arroyo 1987). El cóndor y el puma (león americano) son consagrados de mayor prestigio $y$, muchas veces, el «Apu Wamani» se transforma en ellos o cabalga para aligerar su recorrido e inspeccionar su territorio para beneficiar a los cumplidores o sancionar a los infractores. El halcón (waman), el cernícalo (killinchu) y el picaflor (siwar qente) son aves sagradas de respeto que dan suerte, mientras el zorro, la vizcacha, el zorrino y la vicuña son animales de carga de los apus, para intercambiar sus riquezas con sus hermanos y amigos de la región o para competir con otros contrincantes de su mismo rango de otras regiones, a fin de prestigiar y definir sus fronteras culturales (Sánchez 2015, Arroyo 2008).

El hábitat de los loros o del perico de cabeza roja de la sierra y la costa son siempre de la zona templada, quechwa o yunga, asociados a la siembra del maíz y/o cosecha de los choclos, que por desearle pesimistamente fue sancionado por "Cuniraya»: «Tú caminarás gritando siempre demasiado; cuando digas: destruiré tus alimentos, los hombres, que han de odiarte, te descubrirán por los gritos y te espantarán; vivirás padeciendo" (Ávila 1996: 27). Enfatizando este castigo, los loros son odiados por los cultivadores del maíz de los valles y quebradas, porque tienen que dedicar un plus para espantar o recargar la tarea a los niños o muchachos ahuyentadores con sonidos de lata en los tiempos del choqllo (choclo) de las «michkas» (siembra de primicia) para los festejos de los carnavales y/o la semana santa. Aunque, también son apreciados como las mascotas en los hogares con niños y jóvenes cazadores.

Además, los loros viajan y atacan en bandadas las chacras de choclos, pero son rápidamente detectados por sus gritos exasperados. Aunque son los viajeros desde siempre que trazaron las rutas de caminos intrarregionales del «Qapaq Nan», para transitar por las abras y unir las regiones económicas, las culturas y los pueblos étnicos de la costa, sierra y selva desde tiempos inmemoriales en busca de alimento; es la misma ruta de los antiguos y actuales comerciantes o de los llameros en la diligencia del trueque.

Durante el trabajo de campo se percibió en la estancia del "Apu Wamanrasu» de la comunidad de Santa Bárbara de Huancavelica (Arroyo 2016), por allí pasa el camino inka rumbo al sitio administrativo yunga de «Tambo de Mora» de San Clemente de Pisco-Ica, cuenca productora de maíz y variedad de verduras, donde es común ver y escuchar el griterío de los loros de cabeza roja, trasladándose en bandadas desde el valle de Huanta-Ayacucho y/o de las cuencas 
de Acobamba y Lircay, zonas productoras de variedades de maíz, molle y frutas apetecibles.

Paralelamente al tránsito de los loros en el mes de julio y agosto se observa a menudo a los comerciantes comuneros altoandinos transportar el maíz de Lircay en vistosas llamas de carga o acémilas, de los pueblos de San José de Astobamba o del distrito de Santa Ana y otras comunidades alpaqueras de Castrovirreina, quienes almacenan comprando y/o intercambiando con sus tubérculos, tejidos de la fibra de llamas y de ovejas, como manejo de los pisos ecológicos; mientras, la lana de alpaca se destina selectivamente para la exportación (Arroyo 2016). Del mismo modo, se encuentra recuas de llamas viajeras en la estación del ferrocarril de la ciudad de Huancavelica, viajando desde Choqlloqocha a la cuenca del río Mantaro para abastecerse del maíz, como también en el pueblo de Choqlloqocha9 otro comunero de Qarwancho arribó en una camioneta con varios sacos de maíz y cuya esposa aguardaba con recuas de llamas de carga para trasladarse de retorno a su comunidad de origen, luego de varios días de ausencia.

Pareciera curioso o algo irracional, para la mentalidad urbana de transporte moderno, ver a los pobladores altoandinos trasladándose día y noche muchas jornadas a pie o a lomo de bestia, arreando sus recuas de llamas con vistosas cintas y al sonido de sus esquelas ${ }^{10}$ (campanillas), no solo por lograr el almace-

8 Es el Schinus areira, árbol de los zonas templadas y calientes muy arraigada en la sierra andina del Perú y de Sudamérica. Conocido también por «molle», árbol de la vida, pimienta del Perú, falsa pimienta, cullash, huigan, huiñan, maera, orqo mulli, etc. Su fruto es muy pequeño de color rojo o rosado (cáscara) en forma de racimos, cuyo fruto verdoso es dulce y muy amargo y picante cuando se mas$\mathrm{ca}$, pero es muy codiciado por los loros bulliciosos que se disputan en bandadas y es ahuyentada por los lugareños que cuidan para cosechar y preparar la agradable "chicha de molle», para los cumpleańos o las grandes fiestas de las comunidades, en reemplazo de la chicha de jora o maíz y de la cerveza industrial. En Huanta y Ayacucho, y en las antiguas rutas de camino, había muchas chicherías de molle, luego fueron reemplazados por la chicha de jora, de siete semillas, markachancho y por la cerveza, gaseosa o agua mineral. Además, el molle es muy codiciado para la medicina y el tinte para los tejidos en las comunidades andinas.

9 Cerca de la ciudad de Acobamba (capital de la provincia) existe otro pueblo llamado "Choqlloqocha» y es reconocido como el distrito maicero de la provincia, por poseer una pequeña laguna sagrada con una "Wanka» en la parte central.

10 Son campanillas de bronce que penden del cuello de las llamas y en especial del guía y en conjunto son bulliciosas que causan admiración a los nińos curiosos y aligera el negocio a los mayores. Esta acción bulliciosa de las llamas y afanoso de los llameros trajinantes de los Andes, es similar a la bandada de los loros bulliciosos que cruzan

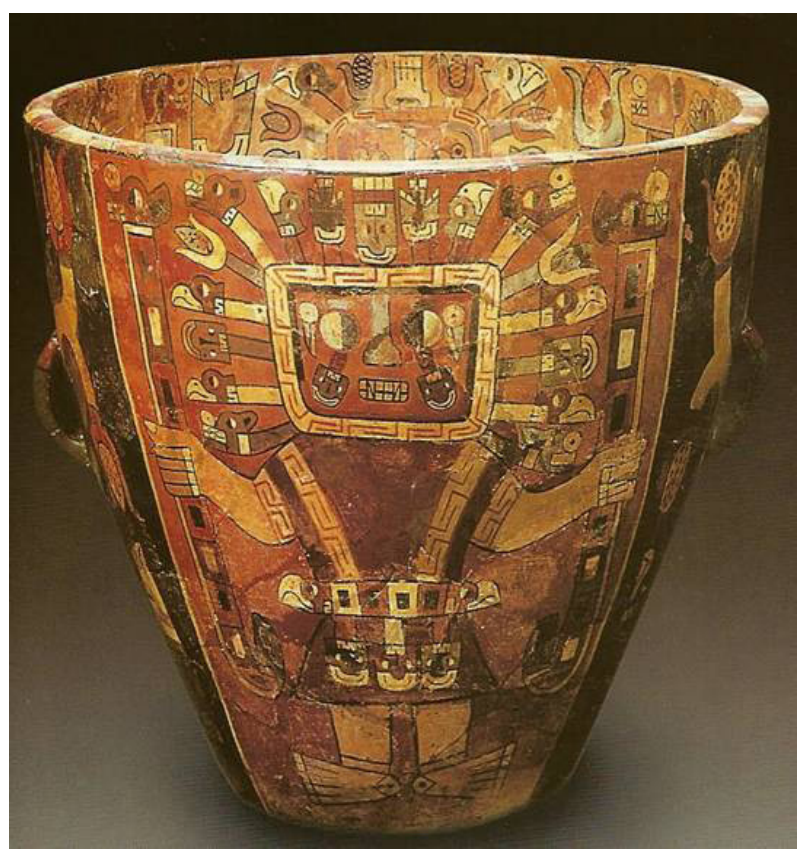

Dios de los báculos y el choqllo

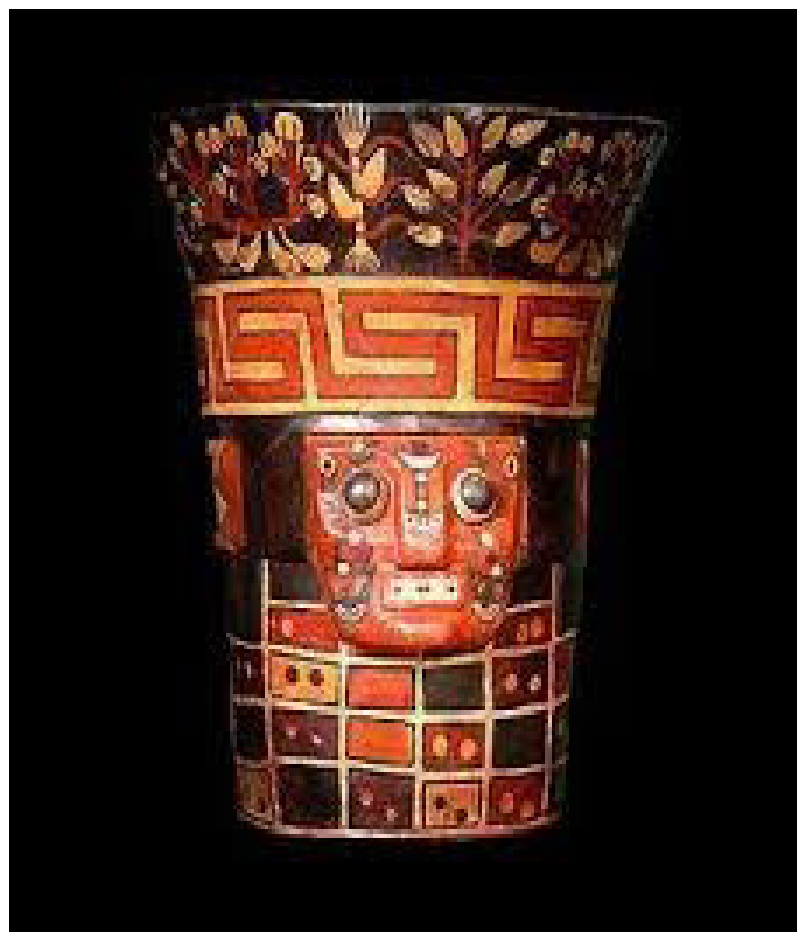

Vaso qero y divinidad del maiz

naje del apreciado maíz, sino, es el ciclo propicio del año (chiraw: estación seca o de cosecha) para viajar al

ansiosos en busca de los choclos por los caminos y las abras de las cordilleras y, por cierto, también son los loros vistosos y atractivos que algunas familias de la zona quechwa tienen por mascotas o para comercializar. 


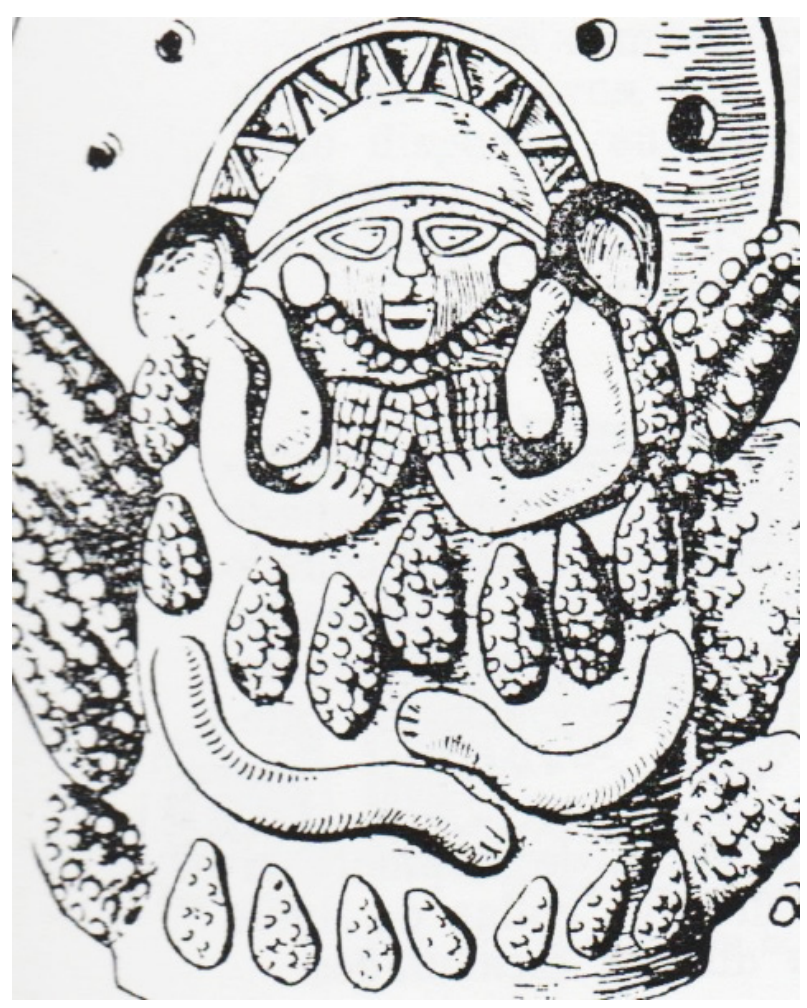

Mamasara

encuentro de amistades y fortalecer lazos de parentesco y solidaridad entre familias espirituales o alianzas de otras comunidades, en el manejo de los pisos ecológicos por la producción y complementariedad económica.

Carrión (1959) trata del «Dios Sembrador», «Dios de la Fertilidad» o «Dios Agrícola» con atributos de agente "sembrando granos de maíz en los surcos de la tierra» de cultivo (divinidad de las semillas y plantas), clasificado entre los «dioses de mayor rango teogónico del Pantheón peruano»; porque en muchas escenas iconográficas están asociados a la serpiente bicéfala, sapos, caimanes, bajo el cielo de arco iris, vestidos cubiertos del grano de maíz y con penachos de la flor (inflorescencia) de maíz. Indicando a un dios que conoce y maneja los fenómenos naturales, el control de los ciclos productivos y la tecnología agrícola: manejo de las lluvias de siembra, cultivo, cuidado y mejora desde la germinación hasta la cosecha y, su respectivo almacenaje con preservación. Por eso los Inkas son portadores del sistema de riego y del «maíz inka» en su dominio, como revela el mito del «Cerro Vicús» de Piura (Arroyo 2004) que muestra a Pachakutiq ordenando construir el canal de riego en gratitud al amor de su doncella.

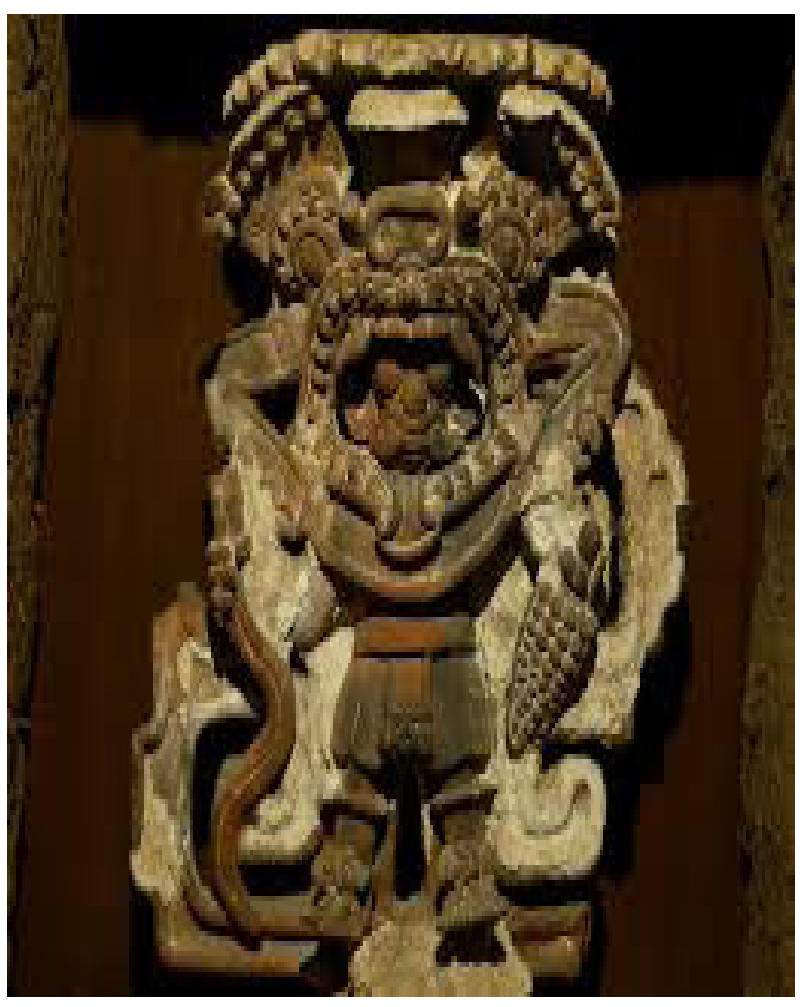

Mamasara

En este proceso de producción, el campesino y en especial los ancianos y los "camayoq" u oferentes de los «Apu Wamanis", son sabios de las comunidades que conocen la llegada de las lluvias de siembra, con anuncios del arco iris o truenos de lluvia. Además, siempre cultiban el maíz en espacios libres para que los rayos del sol fortalezcan y apuren su maduración, si no es así crecen famélicos, amarillentos y al final se secan o no producen por efecto de la sombra de los árboles. Dentro de la simbología climatológica y de culto a la fertilidad, las ranas son los aliados de los agricultores por competir con los grillos que «llaman la sequía»; entonces, deben croar con más fuerza para que los dioses escuchen y hagan llover para asegurar su ciclo de reproducción en los ríos, puquios o lagunas temporales; mientras, los hombres del campo aseguran su siembra y cosecha.

Asimismo, cuando encuentran a las serpientes en el día soleado descansando o paseando en las chacras de maíz, procuran no incomodarlas, porque estarían tomando los rayos del sol y facilitando la madurez de la planta y ocasionalmente encuentran enrollado en su tallo. Dentro del contexto del emparejamiento de los hombres y la idea de la fecundidad, la serpiente es homologado al sexo masculino por su forma y pene- 
trabilidad; de ahí, las serpientes entran o viven en los «sorqay» o zurrones de piedras amontonadas dentro de las chacras, como fruto de la limpieza y preparación de la tierra de cultivo. Incluso, afirman que las piedras crecen dentro de la tierra (madre generatriz) como el maíz con la fuerza germinativa del calor del sol, «Tayta Inti», "dios solar» o "dios del maíz», como Carrión (1995) titula y trata el capítulo IV de su libro.

Además, el arco iris o el «amaru» es la serpiente mítica de los apus (Arroyo 2008), que se extiende como el puente de un cerro a otro para que sus animales sagrados crucen cargando los «dones» para el intercambio con otros de su mismo rango. Seguramente, por esta relación las serpientes bicéfalas aparecen como cinturones de los dioses, para la unión de las montańas o los zurrones de las piedras como los granos del maíz.

La gente del medio rural asegura que la serpiente puede introducirse al sexo de la mujer menstruante, embarazarla o burlarse de las mujeres con hijo: mientras al bebe hace lactar su cola, la serpiente mama a la madre y se cree que la leche le agrada y son serpientes con mucha sangre; además habrían visto sorber la ubre de las vacas con cría. De manera similar, los Apus pueden enamorarse de las buenas mozas de los pueblos, esconderlas en su mansión (dentro de la montaña), embarazarlas o pueden engañarlas regalando mejores padrillos del ganado, buenos granos del maíz (semillas) o convirtiéndolas en las «Mamasaras» prestigiadas, recordadas y evocadas por los ayllus.

Porque en Paucará, Acobamba (Huancavelica), asignan a una señora de muy hacendosa, respetada y temida por considerarla esposa del «Apu Wamani Saqsalla» (divinidad principal del distrito), que reside debajo de dicha montaña y, es más, se convierte en la depositaria de los mejores granos de maíz y de los mejores ganados, por lo que muchos desean adquirir de semillas o de padrillos para ser acaudalados (Arroyo 2008); como en las ceramografías precolombinas aparecen personajes ataviados del maíz sagrado identificados como las «Mamasaras».

Ávila (1966) da cuenta de algunos casos suscitados con las divinidades, gobernantes y personajes con la debida participación de los animales en el entorno social y cultural religioso y de hechicería, durante el primer proceso de extirpación de idola- trías en Huarochirí. Tal es el caso del diálogo de los zorros de abajo y de arriba para que Watiakuri se informe del mal que adolecía y cure al «gran jefe de Anchicocha», quien abríase enfermado no solo por comer la «cancha» o el maíz tostado que saltó a la vagina de su mujer (Tamtańamca), sino por su culpa dos serpientes devoraban la cuerda de su «bellísima casa" y le consumiría un sapo bicéfalo escondido debajo del batán de su vivienda. Y Watiakuri le sanó a condición de casarse con su hija Chaupiñamca, como una estrategia para asegurar el ingreso secreto de su padre Pariaqaqa (Pariacaca) y conquistar la región cisandina sureña.

Lo que indica que tanto la serpiente como el sapo son vigilantes del maíz sagrado dado a los gobernantes o a la población para su buen cuidado y, además, el maíz está relacionado con los dioses y por ende con el varón o en su defecto, indica que hay normas de espacios restrictivos en el uso y consumo de las semillas sagradas; por tanto, la mujer es antinomia al sexo y al poder masculino o al prestigio y autoridad de los dioses. Sin embargo, también se registra la existencia de las mujeres consagradas con rango menor como las "Mamasaras» (Madre del maíz) y hoy en día aún asignan a las mazorcas mellizas como la «madre del maíz» y/o es la «illa» (qonopa) que protege y da suerte a la familia para que el maíz permanezca y no se retire a otro lugar u hogar. Por eso dedican sitio preferencial dentro del «troje» o "pirwa» (depósito) para su resguardo y también destinan la mejor parcela en nutrientes para la siembra del maíz o es la «sara chakra» (tierra de maíz); porque son consideradas semillas engreídas que exige mantención y cuidado especial en el trato y en la producción, como las mujeres, para asegurar la manutención de la familia, comunidad y para el pago a los principales Apus de la región: "comida de los dioses".

También, en la iconografía del «Dios Pachaqamaq" (Pachacamac) se observan mazorcas de maíz pender del cinturón, lo que muestra ser dios creador, domesticador y proveedor de las plantas alimenticias. Aunque, según el mito de Calancha (Pease 1982: 79), al criar a la pareja humana dejó morir de hambre al hombre y la mujer reclamó al «Dios Sol», quien le abasteció y le dio un hijo semidios; pero, Pachaqamaq contrariado «lo mató despedazando en menudas partes a su hermano" y, luego: 
Sembró los dientes del difunto y nació el maíz, semilla que se asemeja a los dientes; sembró las costillas y huesos, nacieron las yucas, raíz que redonda tiene proporción en lo largo y blanco con los huesos, y las demás frutas que son raíces. De la carne procedieron los pepinos, pacaes, y lo restante de sus frutos y árboles, y desde entonces ni conocieron hambre, ni lloraron necesidad, debiéndosele a Dios Pachacamac, el sustento y la abundancia, continuando de suerte su fertilidad la tierra, que jamás ha tenido con extremo hambre la posteridad de los Yungas.

Arriaga (1999: 25-26, 37-38) inventarió el resultado de la campaña de extirpación de las idolatrías en el Perú entre 1617 y 1618 y cuantifica la destrucción del sistema religiosa andino prehispánico, mostrando lo ejecutado por la comisión religiosa: 5694 personas confesadas, 6679 ministros apresados, 603 wakas principales destituidos 3418 conopas, 45 mamasaras y otras 89 wankas y 617 mallkis derribados, 63 curanderos castigados, etc. Asimismo, por la importancia de la función religiosa del maíz especifica la variedad en su representación como: «axomamas", «miczasara» (mesasaras), «huantayzara» (Huanta sara) «hayriguazara» destruidos o quemados.

En cuanto a las «zaramamas» distingue tres tipos por su elaboración: «muñeca hecha de cañas de maíz», otra "vestida como mujer con su anaco» y «lliclla» que tendría la «virtud de engendrar y parir mucho maíz" y la tercera son de "piedras labradas, como choclos o mazorcas de maíz, con sus granos relevados». A dos mazorcas juntas consideran como las "principales zaramamas» y evocan como la «madre del maíz» o son los "huantayzara» o "ayrihuayzara», como ahora identifican por las «saramamas», y la festejaban con la fiesta de "Ayrihua»: bailaban con las cañas de maíz y las ramas de sauce y al final «quemaban y sacrificaban a Libiac» para que beneficie con la buena «cosecha».

Igualmente, hoy bailan con los tallos del maíz tierno o de "michka» en la fiesta santoral de los «Compadres y Comadres» y/o en el «carnaval»: preparan los «killis» o las "wayunkas» de choclos y frutas en el valle de Huanta (Ayacucho) y en los distritos de Acobamba y Lircay (Huancavelica), luego danzan en parejas elegidas alrededor del «árbol del carnaval adornado" hasta derribarlos con un hacha, para que la concurrencia en masa dispute y logre algún adorno del árbol (choqllos, frutas, ropas, juguetes, etc.), de inmediato se desata una guerra alegórica de parejas jóvenes de cada pandilla o banda (de familias o de barrios), lanzándose a las piernas proyectiles de tuna, durazno y lúcuma verdones, además con ortiga y talco se embadurnan la cabeza hasta quedar agotados, acabando el «corta monte» de la tarde y estar expeditos para continuar el día siguiente en otra casa, en un barrio o en el pueblo vecino.

Los carnavales son fiestas de los moceríos por antonomasia, también es fiesta de "Mamacha Kanty» o "Muchuy Warakaq" del mes de febrero, es decir la «mamacha que arroja la escasez o hambruna» del ciclo y apertura los tiempos de saciar el hambre con los primeros frutos del año (primicias de choclo o michka sara) y los agradables "yuyos» (ataqo y nabus) o hierbas del campo que ya abundan con las lluvias de la siembra como la "tuna» en las quebradas q'echwas o de clima templado.

Del mismo modo, Arriaga singulariza el culto a la «Pachamama» como la divinidad reverenciada por las mujeres en el tiempo de la siembra y de la cosecha, derramando el líquido vital de la chicha de maíz o «jora» y hoy sigue utilizándose para el "pagapu» o rito de propiciación para la fiesta del agua o para la siembra grande, donde siempre la mujer es la semillera en la siembra del maíz. También los mejores granos o de «mesa-sara» (mazorca y granos de maíz de dos o más colores) son seleccionados considerándose sagrados para la «semilla», como antiguamente las «mazorcas de maíz que salen muy pintadas» identificaban como la «miczasara», «mantayzara», «caullazara» o «piruazara» que eran «montones de maíz», como los «zurrones de piedra». Igualmente harían con las «axomamas» o la «madre de las papas», cuando en la cosecha encontraban las papas unidas desde su yema en racimos eran como los «kuri» (mellizos o hijos del rayo o de Libiac), símbolo de abundancia en la mentalidad agraria de los pueblos andinos.

\subsection{La religion andina: los apus como dios protector y dispensador de los pueblos}

a. Los apus, dios dispensador de la vida: de plantas, de animales $y$ de pueblos. En principio, todos los mitos o relatos religiosos y las actividades rituales religiosas referidos a los dioses o entes divinos, aún burdo en su forma y culto, sean correspondientes a tiempos arcanos o a las civilizaciones agrarias como a las sociedades industriales o de la cuarta revolución 
industrial (inteligencia artificial), todos en cuanto corresponden a los hechos religiosos pensados, reflexionados y propositivos, se trata de una religión y de una realidad social objetiva y subjetiva de los pueblos o sociedades humanas de su tiempo.

Por otro lado, todas las divinidades supremas o mayores están vinculadas de algún modo a la fundamentación y creación del mundo, de las plantas y animales, de los humanos y de las cosas que conforman este mundo o el otro mundo, del cuerpo como del alma, como una forma de justificar la autoridad y poder o para legitimar el espacio sagrado a diferencia de lo profano o de los «otros». Incluso, son los inventores de la tecnología y los dadores del conocimiento como lo hacen los padres, maestros o las generaciones mayores para su continuidad con reajustes y cambios de acuerdo a la necesidad y capacidad o con transformaciones por difusión o imposición hegemónica en la línea del proceso histórico y cultural de los pueblos y sociedades simples y complejas, antiguas y modernas, tanto en el Perú como en otras partes del mundo.

Durkheim (1968: 8) zanjó al señalar que los «ritos más bárbaros o los más extravagantes, los mitos más extraños traducen alguna necesidad humana, algún aspecto de la vida individual o social». Y en líneas siguientes fue concluyente al decir: «No existen pues, en el fondo, religiones falsas. Todas son verdaderas a su modo: todas responden, aunque de maneras diferentes, a condiciones dadas de la existencia humana».

Por lo que las instituciones religiosas no siempre formaron los fastuosos templos o tablas de dogmas refinadas y oficializadas por un sistema de poder; sino, los sacerdotes u oferentes aleccionados por los feligreses crearon los oratorios y el sistema religioso para la tarea del sistema de creencias y prácticas religiosas de la comunidad; así como los alumnos y profesores son los verdaderos formadores de la instituciones educativas para el progreso y desarrollo y no el local ni los modelos extraños perturbantes.

Entonces, la etnografía del sistema simbólico del arte iconográfico precolombino, donde se representan personajes centrales o divinidades principales en distintas posturas controlando y operando las plantas y animales sagrados como arquetipos instructivos reproducibles para la comunidad, cuyas cualidades representan y significan la domesticación y cultivo de las plantas comestibles en relación con el conocimiento del ecosistema: configuración geográfica, climas y altitudes, ciclos de lluvia y sequía, fenómenos atmosféricos, movimiento de los astros y de los animales y sobre todo, sabiduría de la acción germinador del sol en la simbología del culto a la fertilidad, que es para legitimar su prestigio y poder en la red del manejo de los diversos nichos ecológicos del mundo andino.

Por eso es representado como el dios productor y benefactor, «Dios Sembrador», «Dios de la Fertilidad» o «Dios Agrícola» del maíz sagrado, yuca, tubérculos o de las frutas (Carrión 1959) y también es el dios de la sequía, escasez o sancionador de su creación o dominio, que se le personifica en la figura antropomórfica, zoomórfica, fitofórmica o rodeado de plantas y animales más fieros y silvestres que atemorizan o familiarizan a sus feligreses para lograr su espacio cultural y estructura de poder.

Estos mismos atributos y poderes del dios antiguo encontramos en la omnisciencia y omnipotencia de los «Apu Wamanis», «Jirkas», «Achachilas» o dioses andinos que fusionan las nociones de clasificación y organización del universo (Arroyo 1987); de ahí y de manera singular personifican algunas plantas y animales de cultivo y crianza vital como prototipos para el sistema ritual de los sacerdotes, oferentes y de las comunidades.

Incluso, así como para los cristianos el paraíso se encuentra en el cielo como un arquetipo de estilo de vida en condiciones de igualdad, con bonanzas y armonías o es la "ciudad de dios" de San Agustín; también en la cosmovisión andina las montańas sagradas son las moradas oficiales de los Apus, en cuyo interior está el templo o el palacio repujado de oro y plata (Qorikancha) y es el prototipo de un pueblo con bienes colectivos y es fuente de las mejores plantas y de los animales como buenos padrillos, que ocasionalmente libera a este mundo para beneficiar a los afortunados o cumplidores con sus derechos y obligaciones en la tarea social de este mundo.

Por esta contingencia, en las noches del 1 de agosto, los conocedores de la tradición trajinan atentos a ser escogidos o lograr el acceso a dicho templo para su debida instrucción y conversión en los afamados "pongos», "camayoq", "yatires» o sacerdotes para el servicio de los dioses andinos y ser buenos intermediarios con las comunidades andinas; incluso los «danzantes de tijera» transitarían por las duras 
pruebas de los Apus. Similar simboliza la «Semana Santa» en Piura, donde el tiempo se suspende de manera implícita y apertura los espacios sagrados o las «wakas» (sitios arqueológicos) para que los «huaqueros» puedan huaquear y hurtar la riqueza sin riesgo alguno de enfermarse o ser eliminado por los «gentiles» o los «awelos» (abuelos, antepasados).

Esta representación sobre las divinidades, los espacios sagrados definidos y la instrucción categórica de los intermediarios, para la educación de las nuevas generaciones, son algunos indicadores de la continuidad de los antiguos dioses precolombinos en la figura de los actuales dioses andinos, identificados con diferentes nombres y rangos jerárquicos que demarcan espacios culturales o las regiones étnicas del mundo andino.

b. Conflicto y poder de los dioses andinos. Es pan andino la concepción de la estructura organizacional de los apus y su correspondiente dominio y legitimación de los espacios culturales dentro del esquema de parentesco y sistema de alianzas, como Arguedas (1981) revela que el "Apu Qarwarasu» es la divinidad mayor de la región frente al "Apu Pedro Orqo" de poder local para Puquio. Del mismo modo, encontramos la jerarquía de los Apus Wamanrasu, Qarwarasu y Rasuwillka como hermanos de mayor a menor y corresponden a los departamentos de Huancavelica y Ayacucho, respectivamente (Arroyo 1987, 2008, 2016); y siempre mantienen relaciones de competencia e intercambio de sus respectivos bienes agropecuarios para garantizar y dinamizar el mercado local y regional de los pueblos interétnicos, desde tiempos remotos.

Valderrama y Escalante (1988) evidencian en el valle de Colca las relaciones jerárquicas competitivas entre los «Mallku Mismi» y «Mallku Waranqate», para beneficiar a sus comunidades, incluso, cada divinidad posee su respectiva esposa, hijos y cuñados, como un modelo arquetípico reproducible para las familias campesinas de la región. Igualmente, Sánchez $(2015,2016)$ muestra a los apus mayores y menores vinculados en tramas de competencias, alianzas y disputas en la región de Cusco, como reproduciendo los sistemas de poder, las reglas de matrimonio, tramas de las parejas, confabulaciones de las familias y de las cotidianidades de las comunidades andinas.

\section{c. Epitetos de los dioses y de los especialistas andinos.} Dios en griego (forma genitiva de Zeus) y deus en latín es el «brillo» o «resplandor» para denominar la cualidad de los seres espirituales poderosos y omniscientes o "ser supremo creador del universo» para las religiones monoteístas y en la lengua "sanscrita» (hindú) es "Deva» como "ser celestial». Conceptos y cualidades acuñados por los teólogos y filósofos antiguos y modernos para calzar la existencia de «Dios», cuyo sinónimo es «deidad» o «divinidad» suprema o principal para asignar a las creencias religiosas politeístas.

Esta clasificación tiene sentido etnocéntrico, peyorativo y de señal hegemónica o racial encubierto por el desarrollo industrial y progreso de la modernidad urbana, porque se relaciona con la idea del absolutismo medieval de lo eterno, perfecto, único, absoluto, todo lo sabe con lo poderoso, superior, tecnológico o por la razón única. Cuando ya mostraron que también los dioses se equivocan, olvidan, lloran, compiten, son ricos o pobres, y sufren por su libertad o se humillan ante los dominantes como los humanos cuando son avasallados por otros hegemónicos. Los dioses necesitan de su creación para seguir existiendo y cabalgando, así como los hombres andinos viven con sus dioses o apus en mutuos requerimientos; pues, deben cumplir con sus pagos y evocaciones en los tiempos prescritos y espacios designados por la tradición, para seguir resguardando las relaciones recíprocas y sistemas de solidaridad mutua y complementaria, como exige la red de relaciones y dependencias del sistema ecológico.

En el mundo andino encontramos numerosos términos y conceptos sugestivos para identificar y legitimar a los dioses andinos en diversas lenguas y dialectos antiguos y actuales que expresan y representan las cualidades más extraordinarias de los seres protectores y benefactores de la población; como un avance registramos algunas designaciones desde la cálida región norte de Piura hasta los confines de Bolivia y Chile: Encanto del cerro, Tayta Amito, Wakapong, Rahu, Jirka, Aukillo, Tayta Ulqu, Tayta Auki, Tayta Wamani, Apu Wamani, Tayta Yaya, Orqo Yaya, Apusuyo, Roal, Machula, Tata Mallku, Uywiri o Achachila, entre otros nombres (Arroyo 2004, 2009).

Del mismo modo, las designaciones a los intermediarios o sacerdotes varían según las lenguas y dialectos regionales como por las especializaciones fun- 
cionales de la tradición cultural de los pueblos y entre otros tenemos a: Waringueño, Maestro, Curandero, Pongo, Camayoq, Auki, Alto Mesayoq, Paqo o Yatiri, y cada cual se distingue según su centro de formación y especialización; aunque en las ciudades modernizadas fueron velados con carga cultural peyorativa de «brujos», «hechiceros», "hierberos» o "curanderos» $y$ en los últimos tiempos, comercialmente, cambiaron por "chamanes», debido a la percepción equivocada y facilitada por algunos estudiosos extraviados en la historia cultural religiosa. Sin embargo, hay un incesante afán de recuperar y visibilizar la cultura matriz andina por los movimientos nativistas y un despertar de los miembros de las instituciones culturales del estado que vienen reproduciendo o recreando algunas manifestaciones religiosas como es el rito de propiciación a la «Pachamama» y los «Apus» del mundo andino.

\section{Bibliografía}

Arguedas, José María (1981). Formación de una cultura nacional indoamericana. México: Siglo XXI.

Arriaga, Pablo Joseph de ([1621] 1999). La extirpación de la idolatría en el Piru. Cusco: Centro Bartolomé de las Casas.

Arroyo, Sabino (2016). Culto al Apu Wamanrasu. Lima.

Arroyo, Sabino (2014). Las amazonas de Apu Sara-Sara: "Qasiri warmi llaqta» (pueblo de mujeres sin marido). En Investigaciones Sociales. Revista del Instituto de Investigaciones Histórico Sociales, N. ${ }^{\circ} 33$, UNMSM, Lima.

Arroyo, Sabino (2009). Simbología de los dioses andinos: formas de representación y relación de los apus. En Perspectivas Latinoamericanos, N. ${ }^{\circ}$ 6, Centro de Estudios Latinoamericanos, Universidad Nanzan, Nagoya, Japón.

Arroyo, Sabino (2008). Culto a los Hermanos Cristo. Lima: UNMSM.

Arroyo, Sabino (2004a). Los mitos como huellas del tiempo y contacto intercultural. En Revista de Antropología, N. ${ }^{\circ}$ 2, UNMSM, Lima.

Arroyo, Sabino (2004b). Dioses y oratorios andinos de Huancabamba. Lima: UNMSM.

Arroyo, Sabino (1987). Algunos aspectos del culto al Tayta Wamani. Lima: UNMSM.
Ávila, Francisco de (1966). Dioses y hombres de Huarochirí. Ed. bilingüe. Traducción: José María Arguedas. Estudio biobibliográfico: Pierre Duviols. Lima: Museo Nacional de Historia y el Instituto de Estudios Peruanos.

Carrión C., Rebeca (1959). La religión en el antiguo Perú. Lima.

Curatola, Marco y Mariusz Zıolkowski (Eds.) (2008). Adivinación y oráculos en el mundo andino antiguo. Lima: IFEA/PUCP.

Durкheim, Emilio (1968). Las formas elementales de la vida religiosa. Buenos Aires: Editorial Schapire S.R.L.

Eliade, Mircea (1968). El mito del eterno retorno. Buenos Aires: Emecé Editores.

Eliade, Mircea (1961). Mitos, sueños y misterios. Buenos Aires: C.G. Fabril Editorial.

Gadamer, Hans-Georg (1997). Mito y razón. Barcelona: Paidós.

Gluckman, Max (1978). Politica, derecho y ritual en la sociedad tribal. Madrid: Akal.

Graves, Robert (1967). Los mitos griegos. Buenos Aires: Ed. Losada.

Grobman, Alexander (1982). Raíz (Zea Mays). En D. Bonavia, Los Gavilanes. Lima: Editorial AusoniaTalleres Gráficos S.A.

Guaman Poma, Felipe (1980). El primer nueva corónica y buen gobierno. México: Siglo XXI-IEP.

Levi-Strauss, Claude (1990). Mito y significado. Madrid: Alianza Editorial.

Malinowski, Bronislaw (1963). Estudios de psicología primitiva. Buenos Aires: Paidós.

Matos, Ramiro (1994). Pumpu: Centro administ. Inka de la Puna de Junín. Lima: Ed. Horizonte.

Millones, Luis y Renata MaYer (2012). La fauna sagrada de Huarochirí. Lima: IEP.

Molina, Cristóbal de (1959). Ritos y fábulas de los incas. Buenos Aires: Editorial Futuro.

Morote, Efraín (1988). Aldeas sumergidas. Cusco: Bartolomé de las Casas.

Navarro, Víctor (1983). Las tribus de Ancku Wallock. Lima: Ed. Atusparia.

OсноA, Roberto (2002). Montañas mágicas del Perú: El Apu Pariacaca. Lima: Rep. Editorial.

Pease, Franklin (1982). El pensamiento mítico. Lima: Mosca Azul Editores.

Reinhard, Johan (1988). Las líneas de Nazca. Lima: Editores Los Pinos.

SÁnchez, Rodolfo (2015). Apus de los cuatro suyus. Cusco: IEP-CBC. 
SÁnchez, Rodolfo (2016). Apu Sallqantay: Guardián de la naturaleza. Inkari, N. ${ }^{\circ} 1$, Cusco.

Santa Cruz Pachacuti, Joan de (1993). Relación de antigüedades deste reino del Pirú. Cusco: CERA, Bartolomé de las Casas.

SPEnCER, Herber (s/f). La ciencia social. Barcelona: Ed. Atlante.
Sumar, Luis (2018). El origen andino del maíz. Lima.

Valderrama, Ricardo y Carmen Escalante (1997). La doncella sacrificada. Lima: IFEA.

Valderrama, Ricardo y Carmen Escalante (1988). Del tata mallku a la mama pacha. Lima: Desco. 